\title{
Treatment of Hypertension with Clonidine
}

\author{
A. I. MACDOUGALL, ${ }^{*}$ R.D., M.B., M.R.C.P.ED. ; G. J. ADDIS, ${ }^{*}$ M.D., M.R.C.P.ED. ; N. MACKAY, $\dagger$ M.B., M.R.C.P.ED. \\ I. W. DYMOCK, $\ddagger$ M.B., M.R.C.P.ED. ; A. G. G. TURPIE, $\$ M.B., M.R.C.P. ; D. L. K. BALLINGALL, $\|$ M.B., M.R.C.P.GL.ASG. \\ W. J. MACLENNAN, M.B., M.R.C.P. ; B. WHITING, ${ }^{* *}$ M.B., M.R.C.P. ; J. G. MACARTHUR, †† M.C., M.B., F.R.C.P.GLASG.
}

\begin{abstract}
Summary: Clonidine, in a daily dosage of $0.15-4.8 \mathrm{mg}$., $\checkmark$ effectively lowered systolic and diastolic pressures in 26 out of 28 inpatients with moderate to severe hypertension, including five with primary renal disease. The action of the drug did not depend on posture and was not associated with reduction in renal function. Sideeffects were not severe, but mental changes occurred in four patients.
\end{abstract}

Clonidine is a useful alternative to currently available antihypertensive drugs, but further evaluation of its longterm efficacy is required.

\section{Introduction}

Clonidine hydrochloride is an imidazoline derivative, chemically related to tolazoline and phentolamine. When tested as a nasal decongestant it reduced blood pressure and caused sedation, dry mouth, and bradycardia (Graubner and Wolf, 1966). Extensive pharmacological investigations have shown that its action differs from that of other antihypertensive drugs. It has no direct vasodilator action, it does not deplete catecholamine stores and there is no block of ganglionic, post-ganglionic, or $\alpha / \beta$-adrenergic transmission. It has vasoconstrictor and central depressant effects. It increases vagal and diminishes sympathetic tone, while all its actions are reversed by an $\alpha$-adrenergic blocker. Its main peripheral action may be to reduce responsiveness to direct vasoconstriction (Zaimis and Hanington, 1969; Lancet, 1969).

Clinical trials of clonidine have been reported from Europe (Bock et al., 1966; Frank and von Loewenich-Lagois, 1966; Grabner et al., 1966; Kochsiek and Fritsche, 1966; Lieb and Ridders, 1966; Michel et al., 1966; Iisalo and Laurila, 1967), America (Davidov et al., 1967; Onesti et al., 1969; Smet et al., 1969), and Australasia ( $\mathrm{Ng}$ et al., 1967; Raftos, 1969), and several workers have carried out acute haemodynamic studies (Barnett and Cantor, 1968; Muir et al., 1969). These show that clonidine lowers the blood pressure in all grades of hypertension, irrespective of posture. Its toxicity and sideeffects compare favourably with those of other antihypertensive agents, and it does not appear to diminish renal function, even when this is already impaired.

Our study of 28 inpatients was designed to test the therapeutic value of the drug and to examine postural influences, side-effects, and long-term changes in renal function. In most cases outpatient treatment was subsequently maintained for up to two years.

Consultant Physician

+ Senior Lecturer.

Formerly Lecturer. (Now Senior Registrar, Liver Unit, King's College Hospital, London S.E.5.)

$\oint$ Formerly Lecturer. (Now Senior Registrar in Medicine, Royal Infirmary, Glasgow C.4.)

Formerly Assistant Lecturer. (Now Instructor in Clinical Pharmacology, Tufts University, Boston, U.S.A.)

I Formerly Lecturer. (Now Senior Registrar in Geriatric Medicine, Western Infirmary, Glasgow W.1.)

** Lecturer.

t† Senior Lecturer (Pollok Lecturer).

Department of Materia Medica and Therapeutics, University of Glasgow, and Division of Clinical Medicine, Stobhill General Hospital, Glasgow N.1.

\section{Patients and Methods}

Patients were selected for treatment whose diastolic blood pressure at rest consistently exceeded $110 \mathrm{~mm}$. $\mathrm{Hg}$, and who had received no previous treatment, or whose previous drug treatment was unsatisfactory on account of side-effects or poor control of blood pressure. Five of the 28 patients had underlying renal disease and the others had idiopathic hypertension. The severity of the disease was assessed initially according to the retinal signs and the clinical, radiological, and electrocardiographic evidence of heart involvement, as well as by routine urine tests, serum urea values, and creatinine clearances.

When possible, treatment was delayed for a week or more to record baseline blood pressures until these were reasonably constant. Inpatient treatment was continued until dosage was thought to be optimal; this usually took at least two weeks. On discharge patients were seen weekly for the first few weeks and then at intervals of up to six weeks as appropriate.

The initial dose of clonidine was 75 or $150 \mu \mathrm{g}$. orally twice daily with total daily increments of 75 or $150 \mu \mathrm{g}$. every second day if indicated; the total daily dose was divided into three to five fractions. Dosage was altered as required at outpatient visits, and in some cases $5 \mathrm{mg}$. of bendrofluazide was then added.

Inpatient blood pressures were recorded twice daily after the subjects had been lying at rest for at least 30 minutes and then after standing for two minutes. In some patients the erect reading was repeated after 10 cycles of a two-step exercise test. Outpatient readings were made without any attempt to ensure basal conditions as this was thought to give a better indication of the real efficacy of the drug. Routine haematological and biochemical tests were arranged at intervals, including serum urea and electrolyte levels and liver function tests. The initial assessment, including chest $x$-ray examination, electrocardiogram, and creatinine clearance, was repeated after about six months' treatment.

The baseline blood pressures before treatment were compared statistically with those during the inpatient period when dosage was optimal, and also with the outpatient readings. The pairs of readings in the recumbent and erect postures were also compared.

\section{Results}

The changes in mean systolic and diastolic pressures of the individual patients during inpatient treatment are shown in Figs. 1 and 2. In every case both systolic and diastolic pressures were reduced-significantly in all but two cases $(P<0.01$, Student's $t$ test). The mean decreases for the whole group were $54 \mathrm{~mm}$. $\mathrm{Hg}$ (systolic) and $22 \mathrm{~mm}$. $\mathrm{Hg}$ (diastolic). Of 24 patients who continued to take the drug as outpatients, 11 had outpatient readings of systolic pressure and 10 of diastolic pressure significantly lower than the pretreatment inpatient readings. (This is a severe test of the effect of the drug, since inpatient records were obtained under conditions more nearly basal.) Eleven patients had previously been treated with other powerful hypotensive agents (ganglion blockers, methyldopa, guanethidine, bethanidine, debrisoquine), and in seven of these outpatient 
treatment with clonidine gave more satisfactory control of the blood pressure.

No retinal appearances deteriorated during treatment; two of the four patients with grade IV and one of the two with grade III retinopathy showed improvement. One man had progression of renal and cardiac complications, with increased cardiomegaly, electrocardiographic deterioration, and a fall in creatinine clearance from 107 to $78 \mathrm{ml} . / \mathrm{min}$. Of five others with radiological evidence of severe cardiomegaly three improved, and of 11 with electrocardiographic features of hypertensive heart disease five improved.



during the period of optimal dosage of clonidine in hospital.

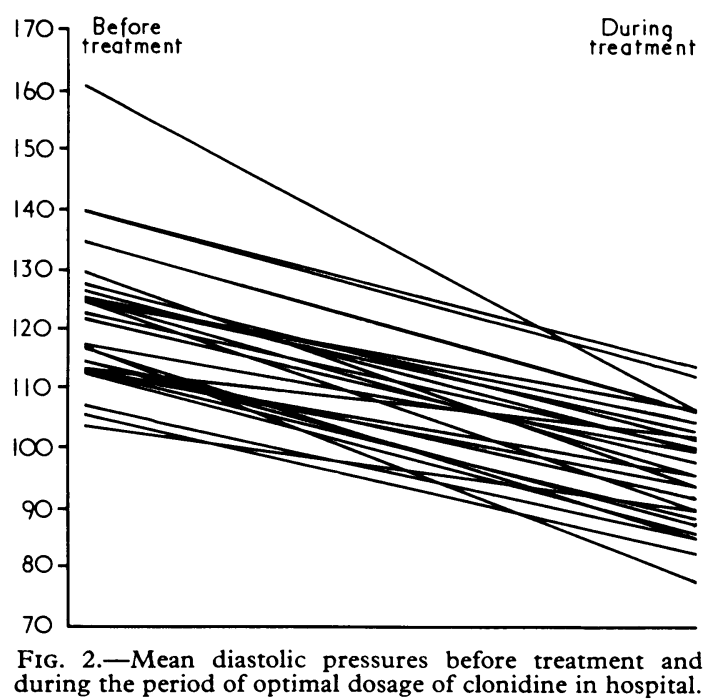

Two out of six patients improved their low creatinine clearance values from 36 to 95 and from 42 to $53 \mathrm{ml}$./min. respectively. The remaining four, and the four with normal creatinine clearances, showed no change.

Postural Effects.-One patient had a significant postural fall in systolic and diastolic pressures with definite hypotensive symptoms while receiving the large dose of $4.8 \mathrm{mg}$. daily. This followed a considerable diuresis from bendrofluazide; 10 days after withdrawal of the diuretic the postural difference in blood pressure was diminishing. No other patient had postural symptoms or a significant alteration in diastolic pres- sure, but two patients showed significant $(P<0.05)$ reduction of systolic pressure on standing (from 185 to 165 and from 202 to $183 \mathrm{~mm}$. $\mathrm{Hg}$, means).

Side-effects and Toxicity.-The side-effects noted are shown in the Table. Haematological findings, serum electrolytes, and liver function tests showed no change attributable to the drug.

Dosage.-The dose required for adequate blood pressure control during the inpatient period ranged widely, from 0.15 to $4.8 \mathrm{mg}$. daily. Only six patients did not need an increased dose as outpatients, the range becoming 0.225 to $6 \mathrm{mg}$. per

Side-effects of Clonidine

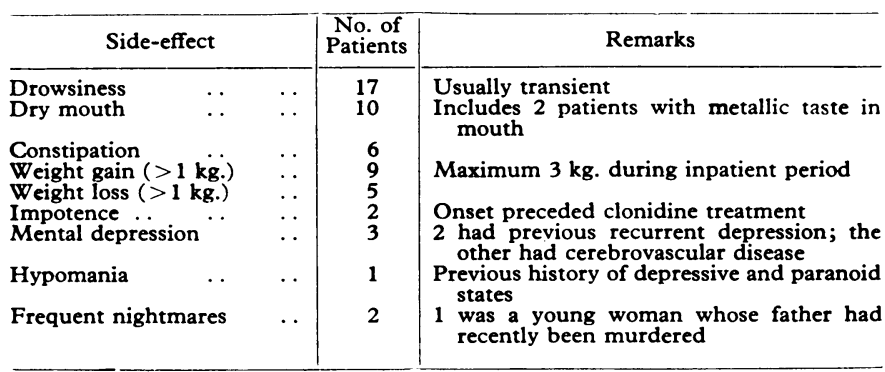

day. Most of the increase in dosage took place during the first few weeks after leaving hospital, but a few patients still needed dose increases even after many months of treatment. Eight patients also received an oral diuretic (usually bendrofluazide, $5 \mathrm{mg}$. daily), and in one case the daily dose of clonidine could then be reduced from 4.8 to $3.6 \mathrm{mg}$. daily. One patient has had 5 or $6 \mathrm{mg}$. of clonidine daily for two years and another $4.5 \mathrm{mg}$. daily for 18 months without apparent ill effect. Fourteen of the 28 patients have discontinued clonidine treatment; four could not attend for follow-up for various personal reasons, three were readmitted elsewhere, two had possible side-effects (impotence, hypomania), one had symptomless hypotension, and four became refractory to the drug in spite of increased doses. Of the latter four, two were resistant to all other drugs tried and one was transferred to other treatment before the maximum tolerated dose of clonidine was reached.

\section{Discussion}

The results of this study confirm that clonidine is an effective antihypertensive agent, even in the accelerated ("malignant") phase of the disease. A wide range of dosage requirement has been shown, and this probably explains the lower success rate reported by other investigators who adopted an arbitrary maximum daily dose of about $1.2 \mathrm{mg}$. Impaired absorption of the drug from the gut may account for the high dosage which some patients need (compare hexamethonium).

An important advantage of clonidine is that its action is not dependent on posture, so that postural hypotension is rarely encountered. Only one of our patients had postural syncope; the main predisposing factor in his case was probably sodium depletion from diuretic therapy. The only other postural effect detected was a symptomless fall in systolic pressure in two patients. Nor did our observations suggest that exercise induced hypotension. Others have also found (Barnett and Cantor, 1968; Muir et al., 1969) that the circulatory response to exercise is not affected by clonidine. Another desirable feature is that clonidine does not reduce renal blood flow or glomerular filtration rate (Onesti et al., 1969), so that, like methyldopa, it is suitable for treating renal hypertension. The five patients with renal hypertension in this study did not differ from the other patients in blood pressure response or dosage requirement.

Side-effects from the drug were not disabling and were often transient; several patients with experience of other 
hypotensive agents said that they felt better with clonidine than with the other drugs. There was no clinical, haematological, or biochemical evidence of serious toxicity, even though several patients received dosage higher than other investigators have recorded. Mental changes, however, appear to be a hazard of clonidine treatment ( $\mathrm{Ng}$ et al., 1967), as might be expected from its central depressant effect. Those with a previous history of depressive illness and those with advanced cerebrovascular disease seem to be especially at risk.

Undoubtedly drug tolerance occurs, especially in the early weeks of therapy. Blood pressure tended to escape from control shortly after the patient left hospital, but higher dosage usually restored satisfactory levels, and thereafter increases of dose were infrequent. It has been suggested (Davidov et al., 1967) that the apparent tolerance is due to sodium retention and can be overcome by adding an oral diuretic. This has not been evident in our limited experience, but the point probably deserves further study.

We are indebted to Dr. Julian H. Shelley, Medical Director of Boehringer Ingelheim Ltd., who made available generous supplies of clonidine for this study.
REFERENCES

Barnett, A. J., and Cantor, S. (1968). Medical fournal of Australia, 1, 87. Bock, K. D., Heimsoth, V., Merguet, P., and Schonermark, J. (1966). Deutsche medizinische Wochenschrift, 91, 1761.

Davidov, M., Kakaviatos, N., and Finnerty, F. A. (1967). Clinical Pharmacology and Therapeutics, 8, 810 .

Frank, K., and von Loewenich-Lagois, K. (1966). Deutsche medizinische Wochenschrift, 91, 1680.

Grabner, G., Michalek, P., Pokorny, D., and Vormittag, E. (1966). Arzneimittel-Forschung, 16, 1174.

Graubner, W., and Wolf, M. (1966). Arzneimittel-Forschung, 16, 1055.

Iisalo, E., and Laurila, S. (1967). Current Therapeutic Research, 9, 358.

Kochsiek, K., and Fritsche, H. (1966). Arzneimittel-Forschung, 16, 1154.

Lancet, 1969, 2, 529.

Lieb, W., and Ridders, K. (1966). Arzneimittel-Forschung, 16, 1610.

Michel, D., Zimmermann, W., Nassehi, A., and Seraphim, P. (1966). Deutsche medizinische Wochenschrift, 91, 1540.

Muir, A. L., Burton, J. L., and Lawrie, D. M. (1969). Lancet, 2, 181.

$\mathrm{Ng}$, J., et al. (1967). New Zealand Medical fournal, 66, 864.

Onesti, G., Schwartz, A. B., Kim, K. E., Swartz, C., and Brest, A. N. (1969). Circulation, 39, 219.

Raftos, J. (1969). Medical fournal of Australia, 2, 684.

Smet, G., Hoobler, S. W., Sanbar, S., and Julius, S. (1969). American Heart fournal, 77, 473 .

Zaimis, E., and Hanington, E. (1969). Lancet, 2, 298.

\title{
Xylene Poisoning: A Report on One Fatal Case and Two Cases of Recovery after Prolonged Unconsciousness
}

\author{
R. MORLEY, ${ }^{*}$ M.B., CH.B., D.I.H. ; D. W. ECCLESTON, $†$ M.B., B.S., M.R.C.P. ; C. P. DOUGLAS $\ddagger$ \\ W. E. J. GREVILLE, $\$ M.A. ; D. J. SCOTT,\| M.B., B.S. ; J. ANDERSON, M.B., B.S., M.R.C.P.
}

\begin{abstract}
Summary: Three cases of xylene poisoning occurred $\checkmark$ after prolonged inhalation of paint fumes. Analysis showed that xylene comprised more than $90 \%$ of the solvent in the paint, the total solvent comprising $34 \%$ of the paint by weight. One patient was dead on admission, while the other two recovered after at least 15 hours' loss of consciousness. Both patients had transient liver cell damage, and one temporary impairment of renal function.
\end{abstract}

\section{Introduction}

Xylene is irritant to the skin and mucous membranes (Johnstone and Miller, 1960; Browning, 1965) and prolonged exposure causes considerable gastrointestinal upset. The principal acute effect of xylene is narcotic (Browning, 1965) though complete unconsciousness is rare and no fatal cases have been reported following exposure to the pure substance or to mixtures containing it.

\section{Case Reports}

Three men aged 54, 52, and 24 were employed by a firm of shipbuilders and were instructed to paint a double-bottomed tank in the engine room of a ship. The paint was to be applied by brush. The space was in the form of a coffer dam surrounding two lubricating oil-storage tanks and was about $17 \mathrm{ft}$. 2 in. wide $(5.33 \mathrm{~m}),. 17 \mathrm{ft} .6$ in. long $(5.43 \mathrm{~m}$.) and $4 \mathrm{ft} .8 \mathrm{in}$. $(1.42 \mathrm{~m}$.) high. It was made up of small cells and access was via two manholes in

* H.M. Medical Inspector of Factories, Northern Division.

† Medical Registrar, Royal Victoria Infirmary, Newcastle upon Tyne. ¥Chief Safety Officer, Swan Hunter Group Ltd., late H.M. Inspector of Factories.

$\checkmark$ H.M. District Inspector of Factories, Newcastle upon Tyne.

|| Demonstrator in Pathology, University of Newcastle upon Tyne.

I Senior Lecturer in Medicine and Honorary Consultant Physician, University of Newcastle upon Tyne and the Royal Victoria Infirmary, Newcastle upon Tyne. the end of the tank. Each manhole measured about $1 \mathrm{ft} .8$ in. by $1 \mathrm{ft} .3$ in. $(51$ by $38 \mathrm{~cm}$.).

Work apparently began at about 10.30 a.m. and though the men were due to finish at 4.30 p.m. it was not until later in the evening that a search for them was made. This continued until 5 a.m. next day, when the three men were found apparently unconscious. Though there was a strong smell of solvent fumes, the rescuers were able to work without breathing apparatus, and at about 6 a.m. the men were taken to the Royal Victoria Infirmary, Newcastle upon Tyne.

\section{Case 1}

This man was dead on arrival. Necropsy, carried out 12 hours after death, showed a well-nourished man with pronounced cyanosis of the head and extremities. The heart weighed $400 \mathrm{~g}$. and showed slight left ventricular hypertrophy. Both lungs were heavy and plum-coloured; the right weighed $900 \mathrm{~g}$. and the left $850 \mathrm{~g}$. The cut surfaces were deeply congested and copious amounts of fluid exuded from them. The liver was congested but otherwise appeared macroscopically normal.

Histological examination of the lungs showed severe congestion with focal intra-alveolar haemorrhage and acute pulmonary oedema with pink-staining amorphous material within the alveolar lumina. The liver showed congestion, with swelling and vacuolation of many cells, confined mainly to centrilobular areas. The brain showed microscopical petechial haemorrhages in both grey and white matter and haemorrhages in Virchow-Robin spaces. There was evidence of anoxic neuronal damage with swelling and loss of Nissl substance.

\section{Case 2}

On admission to hospital this man was unconscious and showed only slight response to painful stimuli. His temperature was $90^{\circ} \mathrm{F}$ $\left(32.2^{\circ} \mathrm{C}\right.$.) and he was shivering intermittently. His face was flushed, there was peripheral cyanosis, and his expired air smelled 